\title{
Inference of Atmospheric Temperature from Measurements with the Ground-based Spectrometer
}

\author{
by \\ Masaatsu Miyauchi and Muneyasu Kano \\ Meteorological Research Institute, Tsukuba, Japan \\ (Received August 12, 1981 ; revised October 2, 1981)
}

\begin{abstract}
A method of inference of the vertical temperature profiles of the lower atmosphere with the ground-based spectrometer is proposed. The measurements were carried out under clear and overcast sky conditions. Under these conditions the inferred profiles by this method agree with those observed by radio sondes. For cases of partly cloudy sky reliable spectral measurements of radiation are difficult to obtain. In such cases, numerical simulations were carried out and the results were found satisfactory except for warm and humid weather conditions.
\end{abstract}

\section{Introduction}

The vertical profiles of atmospheric temperature have been obtained with radio sondes or radiation measurements from the satellites. Both methods, however, have the defect of being limited in space and time. Furthermore the inference from satellite measurements is not adequate to get the detailed vertical profiles of atmospheric temperature in the lowest layer.

On the contrary, the inference of the vertical profile of atmospheric temperature in the lowest layer based on radiation measurements with a ground-based spectrometer can be carried out at any time and place we want. It can, therefore, be conveniently used in researches and operations such as soundings of temperature structure in the lowest layer relating to air pollution.

A number of studies on this subject have been made in recent years. Westwater (1972), Miner et al. (1972), Snider (1972) and others derived the atmospheric temperature profiles on the basis of spectral or angular distribution measurements of atmospheric microwave emis- sion in the $60 \mathrm{GH}_{z}$ band of $\mathrm{O}_{2}$. Generally the observing system of microwave emission is relatively more complicated and expensive than that of infrared emission in the $15 \mu \mathrm{m}$ $\mathrm{CO}_{2}$ band region. In addition the emissions in the microwave region have less temperature dependency than those in the infrared region. Consequently the temperature resolution obtained by the measurements of microwave emission is lower than that obtained by the measurement of infrared emission, though the microwave has the merit of transmitting through the cloud.

On the basis of measurements of infrared emission in the $\mathrm{CO}_{2}$ absorption band by the ground-based spectrometer, Wang et al. (1975) obtained the temperature profiles in the lowest layer for clear skies. In cloudy skies some expedients should be taken to remove the effect of clouds on the inference of vertical profile of atmospheric temperature and these were done in the cases of measurements from the satellites (Chahine, 1977; Smith, 1968). These methods, however, do not seem to be applicable to ground-based measurement.

In the present paper is proposed a method 
to infer the vertical profile of atmospheric temperature in clear and especially cloudy conditions on the basis of radiation measurements with the ground-based spectrometer along with some results of observation and numerical simulation.

\section{Theory}

There are some methods to retrieve the atmospheric temperature profiles from radiation measurements. In this study PhillipsTwomey's method is adopted, which does not need statistical data on atmospheric temperature and spectral atmospheric radiation (Phillips, 1962; Twomey, 1963).

The intensity of atmospheric downward radiation at wavelength $\lambda$ and at the ground level $Z_{s}$ in the case of a clear sky is given by

$$
I_{\lambda}\left(Z_{s}\right)=-\int_{Z_{s}}^{Z_{0}} B_{\lambda}[T(Z)] \frac{\partial \tau_{\lambda}(Z)}{\partial Z} d Z,
$$

where $B_{\lambda}[T(Z)]$ is the Planck Function for wavelength $\lambda$ and atmospheric temperatnre $[T(Z)]$ at altitude $Z, \tau_{\lambda}(Z)$ is the transmission function between the surface $Z_{s}$ and the height $Z$, and $Z_{0}$ is the upper boundary above which the downward radiation does not affect the estimation of the vertical temperature profile. In a narrow spectral region such as the $15 \mu \mathrm{m} \mathrm{CO}_{2}$ band the Planck Function at any wavelength $\lambda$ is properly approximated by the Planck Function at a reference wavelength $\lambda_{0}$ in this region as follows (Wark and Fleming, 1966):

$$
B_{\lambda}[T(Z)]=\alpha_{\lambda} B_{\lambda_{0}}[T(Z)]+\beta_{\lambda} .
$$

$\alpha_{\lambda}$ and $\beta_{\lambda}$ are numerical constants depending on wavelength $\lambda$. Substituting Eq. (2) into Eq. (1), we have

$$
g(\lambda)=\int_{z_{s}}^{Z_{0}} K(\lambda, Z) f(Z) d Z,
$$

where

$$
\begin{aligned}
& g(\lambda)=\left[I_{\lambda}\left(Z_{s}\right)-\beta_{\lambda}\left\{1-\tau_{\lambda}\left(Z_{0}\right)\right\}\right] / \alpha_{\lambda}, \\
& K(\lambda, Z)=-\frac{\partial \tau_{\lambda}(Z)}{\partial Z}, \\
& f(Z)=B_{\lambda_{0}}[T(Z)] .
\end{aligned}
$$

Eq. (3) is a Fredholm integral equation of the first kind. The Plank Function $B_{\lambda_{0}}[T(Z)]$ is developed in terms of the Legendre Polynomials (Alishouse et al. 1967), that is

$$
\left.\begin{array}{l}
B_{\lambda_{0}}[T(Z)]=\sum_{j} C_{j} P_{j}(X), \\
X=\left(2 Z-Z_{0}-Z_{s}\right) /\left(Z_{0}-Z_{s}\right) .
\end{array}\right\}
$$

From Eqs. (4) to (7), and considering the measurement errors, $\varepsilon(\lambda)$, Eq. (3) becomes

$$
g(\lambda)=\sum_{j} A(\lambda, j) C_{j}+\varepsilon(\lambda),
$$

where

$$
\begin{aligned}
A(\lambda, j)= & P_{j}(-1)-P_{j}(1) \tau_{\lambda}\left(Z_{0}\right) \\
& +\int_{-1}^{1} \tau_{\lambda}(Z) \frac{\partial P_{j}(X)}{\partial X} d X .
\end{aligned}
$$

Eq. (8) can be represented in the following matrix form:

$$
\boldsymbol{g}=\boldsymbol{A C}+\boldsymbol{\varepsilon} .
$$

In order to remove undesirable oscillation of the solution of Eq. (10), the following two constraints are imposed. One is an assumption that the desired solution $\boldsymbol{C}$ of Eq. (10) will be closest to some trial solution $\widehat{\boldsymbol{C}}$ which is given provisionally. The other is that the desired solution is the smoothest among the solutions of Eq. (10). The constraints are combined to the solution of Eq. (10), which is given as follows (Twomey, 1963; Wang et al., 1975) :

$$
\boldsymbol{C}=\left(\boldsymbol{A}^{T} \boldsymbol{A}+\gamma_{2} \boldsymbol{H}+\gamma_{1} \boldsymbol{I}\right)^{-1}\left(\boldsymbol{A g}+\gamma_{1} \boldsymbol{I} \widehat{\boldsymbol{C}}\right),
$$

where $\boldsymbol{H}$ denotes the smoothness matrix given by Twomey (1963) and matrix $\boldsymbol{I}$ is the unit matrix. The superscript $T$ means a transposed matrix and the constants $\gamma_{1}$ and $\gamma_{2}$ are Lagrange's multipliers.

The intensity of the atmospheric downward radiation at the ground level in cloudy skies is expressed as follows:

$$
\begin{aligned}
I_{\lambda}\left(Z_{s}\right)= & w B_{\lambda}\left[T\left(Z_{c}\right)\right] \tau_{\lambda}\left(Z_{c}\right) \\
& -w \int_{Z_{s}}^{Z_{c}} B_{\lambda}[T(Z)] \frac{\partial \tau_{\lambda}(Z)}{\partial Z} d Z \\
& -(1-w) \int_{Z_{s}}^{Z_{0}} B_{\lambda}[T(Z)] \frac{\partial \tau_{\lambda}(Z)}{\partial Z} d Z,
\end{aligned}
$$


where $w$ is the fractional cloud amount within the field of view and $Z_{c}$ denote the height of the cloud base. The cloud emissivity is assumed to be unity. From Eqs. (2), (7) and (12) the following equation is obtained by using the partial differential equation:

$$
\begin{aligned}
& {\left[I_{\lambda}\left(Z_{s}\right)-w B_{\lambda}\left[T\left(Z_{c}\right)\right] \tau_{\lambda}\left(Z_{c}\right)\right.} \\
& \left.\quad-\beta_{\lambda}\left\{1-w \tau_{\lambda}\left(Z_{c}\right)-(1-w) \tau_{\lambda}\left(Z_{0}\right)\right\}\right] / \alpha_{\lambda} \\
& =\sum_{j} C_{j}\left[P_{j}(-1)-w \tau_{\lambda}\left(Z_{c}\right) P_{j}\left(X_{c}\right)\right. \\
& \quad-(1-w) \tau_{\lambda}\left(Z_{0}\right) P_{j}(1) \\
& \quad+w \int_{-1}^{X_{c}} \tau_{\lambda}(X) \frac{\partial P_{j}(X)}{\partial X} d X \\
& \left.\quad+(1-w) \int_{-1}^{1} \tau_{\lambda}(X) \frac{\partial P_{j}(X)}{\partial X} d X\right] .
\end{aligned}
$$

In order to solve this equation it is necessary to know $B_{\lambda}\left[T\left(Z_{c}\right)\right]$ and $w$. Following is the method to get them from spectral measurements.

The downward intensity $J_{N}$ in the window regions at the surface in cloudy cases is expressed by an equation similar to Eq. (12). This equation can be rewritten as

$$
J_{N}-\eta_{N}=w B_{\lambda}\left[T\left(Z_{c}\right)\right] \tau_{N}\left(Z_{c}\right)\left(1+\delta_{N}\right),
$$

where

$$
\left.\begin{array}{c}
\eta_{N}=-\int_{Z_{s}}^{Z_{0}} B_{N}[T(Z)] \frac{\partial \tau_{N}}{\partial Z} d Z, \\
\delta_{N}=\frac{-\int_{Z_{c}}^{Z_{0}} B_{N}[T(Z)] \frac{\partial \tau_{N}(Z)}{\partial Z} d Z}{B_{N}\left[T\left(Z_{c}\right)\right] \tau_{N}\left(Z_{c}\right)}, \\
N=\lambda_{1}, \lambda_{2} .
\end{array}\right\}
$$

If the ratio of $\tau_{\lambda_{1}}\left(Z_{c}\right)$ to $\tau_{\lambda_{2}}\left(Z_{c}\right)$ is independent of the variations of the cloud height and atmospheric humidity, that is,

$$
\left.\begin{array}{l}
\tau_{\lambda_{1}}\left(Z_{c}\right)=K \tau_{\lambda_{2}}\left(Z_{c}\right), \\
K: \text { constant. }
\end{array}\right\}
$$

From Eqs. (14) and (16), we have

$$
\frac{B \lambda_{2}\left[T\left(Z_{c}\right)\right]}{B \lambda_{1}\left[T\left(Z_{c}\right)\right]}=K \frac{\left(1-\delta_{\lambda_{1}}\right)}{\left(1-\delta_{\lambda_{2}}\right)} \frac{\left(J_{\lambda_{2}}-\eta \lambda_{2}\right)}{\left(J_{\lambda_{1}}-\eta \lambda_{1}\right)} .
$$

Actually $K$ is a parameter depending on the
Table 1. Coefficients $K$ calculated using a model atmosphere of spring and fall at cloud height $2.5 \mathrm{~km}$.

\begin{tabular}{r|rrrrrr}
\hline$\lambda_{1}$ & 7.5 & 8.0 & 9.0 & 10.0 & 11.0 & $12.0(\mu \mathrm{m})$ \\
\hline 7.5 & & 1.02 & 1.03 & 1.02 & 0.99 & 0.94 \\
$\lambda_{2}$ & 0.98 & & 1.01 & 1.00 & 0.97 & 0.90 \\
9.0 & 0.97 & 0.99 & & 0.99 & 0.96 & 0.89 \\
10.0 & 0.98 & 1.00 & 1.01 & & 0.97 & 0.91 \\
11.0 & 1.01 & 1.03 & 1.04 & 1.03 & & 0.94 \\
12.0 & 1.06 & 1.10 & 1.11 & 1.09 & 1.06 & \\
\hline$(\mu \mathrm{m})$ & & & & & & \\
\hline
\end{tabular}

wavelengths $\lambda_{1}$ and $\lambda_{2}$, cloud height and atmospheric condition. In Table 1 are shown the values of $K$ for a model atmosphere corresponding to the mean atmospheric state of spring and fall in the Tsukuba district in Ibaraki prefecture, Japan, where the spectral measurements of radiation were carried out. The calculations were made for the $\mathrm{H}_{2} \mathrm{O}$ rotation band and the continuum band in which the $e$-type absorption (Bignell, 1970 ; Cox, 1973) is also considered. It is desirable in order to determine ceoud temperature $T_{c}$ that the ratio $B_{\lambda_{2}}\left(T_{c}\right) / B_{\lambda_{1}}\left(T_{c}\right)$ inEq. (17) itself be large and that the variation of $K$ small. For this the wavelengths $8.0 \mu \mathrm{m}$ and $11.0 \mu \mathrm{m}$ are the most suitable. The computations of $\delta_{\lambda_{1}}$ and $\delta_{\lambda_{2}}$ by using the model atmosphere contain some errors mainly due to discrepancies of the model atmosphere from the real one. Moreover in the case of a small amount of cloud (say, $w \lesssim 0.1$ ) within the field of view, the estimation of the cloud base temperature becomes more erroneous. The errors in the cloud base temperature due to $\eta_{\lambda}$ are about $0.9^{\circ} \mathrm{C}$ to $2.0^{\circ} \mathrm{C}$ if the model atmosphere of winter and spring (or fall) is used for all seasons except summer. And the errors due to $\delta_{\lambda}$ are less than $0.3^{\circ} \mathrm{C}$ by the calculation under the same conditions.

Fractional cloud amount $w$ can be obtained from Eq. (14) and next will be shown the error in the estimated cloud amount $w$. The uncertainty of $B_{\lambda}\left(T_{c}\right), \Delta B_{\lambda}$ and that of $\tau_{\lambda}\left(Z_{c}\right)$, $\Delta \tau_{\lambda}$ cause errors in cloud amount $\Delta w / w$, 
which is expressed as

$$
\begin{aligned}
\frac{\Delta w}{w}= & -\left\{\frac{\Delta B_{\lambda}}{B_{\lambda}\left(T_{c}\right)}+\frac{\Delta \tau_{\lambda}}{\tau_{\lambda}\left(Z_{c}\right)}\right\} \\
& \cdot\left\{1+\frac{\int_{Z}^{Z_{0}}{ }^{2} B_{\lambda}[T(Z)] \frac{\partial \tau_{\lambda}(Z)}{\partial Z} d Z}{B_{\lambda}\left(T_{c}\right) \tau_{\lambda}\left(Z_{c}\right)}\right\} .
\end{aligned}
$$

The value $\Delta w / w$ versus $\Delta B_{\lambda}$ at wavelength $11.0 \mu \mathrm{m}$ is shown in Fig. 1. From Fig. 1, it is seen that an error of $1^{\circ} \mathrm{C}$ in the estimated temperature of the cloud base results in about a $2 \%$ errorofw. The error of $w$ due to $\Delta \tau_{\lambda}$ is slightly larger than that due to $\Delta B_{\lambda}$, but it does not exceed $3.6 \%$ if the cloud base height is between $1.0 \mathrm{Km}$ and $3.0 \mathrm{Km}$ From the cloud base temperature and the temperature profile of the model atmosphere the cloud height is estimated roughly and then a more correct cloud base height can be obtained by satisfying the following equation:

$$
T\left[Z_{c}\right]_{n}-T_{c} \leqq \Delta T,
$$

where $T\left[Z_{c}\right]_{n}$ is the cloud base temperature from the inferred profile of atmospheric temperature and $T_{c}$ is the temperature of the claud base obtained from Eq. (17) by the procedure mentioned above. Subscript $n$

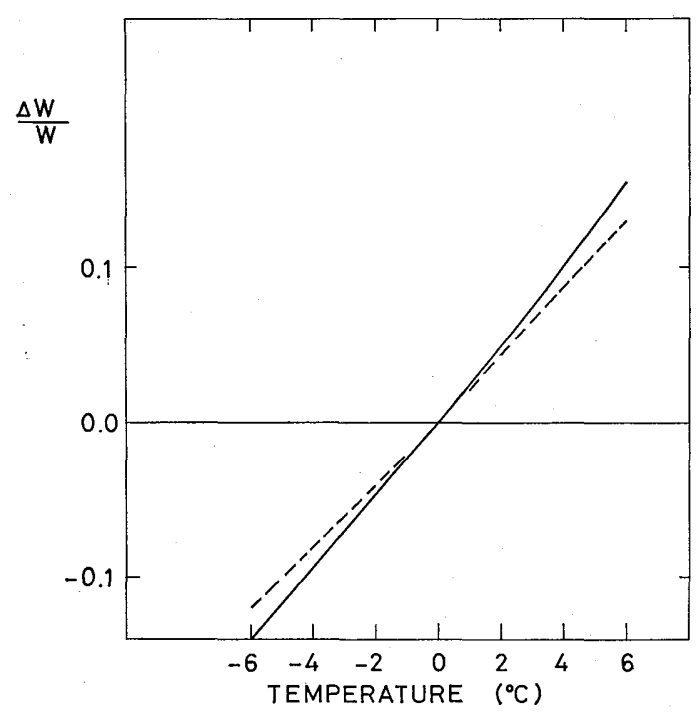

Fig. 1. Estimation error of fractional cloud $\Delta w / w$ due to the error of $B_{\lambda}\left(T_{c}\right)$. Broken line is for the case $T_{c}=-10^{\circ} \mathrm{C}$ and solid line for $T_{c}=-30^{\circ} \mathrm{C}$. denotes the iteration orders of computations in which $Z_{c}$ is changed.

For double cloud layers, the inference of the temperature profile is not dealt with here because of its complexity.

\section{Measurement of spectral radiance}

For this purpose a Czerny-Turner type spectrometer was designed. The spectrometer system consists of several units: a spectrometer, an automatic controller of the spectrometer, a thermal controller of the black body, an amplifier and a data recorder set. A schematic picture of the spectrometer is shown in Fig. 2. A view angle of the spectrometer is about 15 degrees. The radiance from the sky and that from the reference black body are alternately chopped by a gold plated mirror at $8 \mathrm{~Hz}$. Then the radiance is dispersed by a grating ( 60 lines $/ \mathrm{mm}$ ) and reaches to the detector through a band pass filter. The output of the detector which is thermocouples in a vacuum is sent to a lock-in-amp. Observation for one wavelength takes about 35 seconds.

In order to remove errors caused by the thermal emission from the inside of the instrument (mirrors and so on), it is desirable that the whole system be put under a uniform condition at the environmtal temperature. Since it is difficult to maintain such a condition, the following 'subtract method' is employed. The relation between spectral radiation $B_{\lambda}(\theta)$ and resultant output voltage $V_{N}$ is expressed as

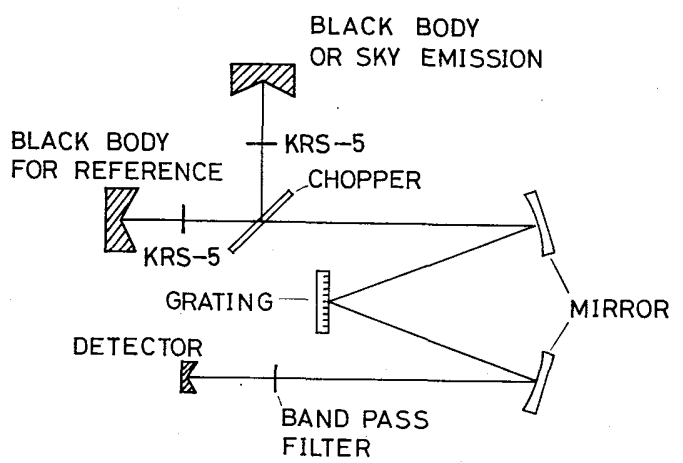

Fig. 2. Schematic representation of a spectrometer. 


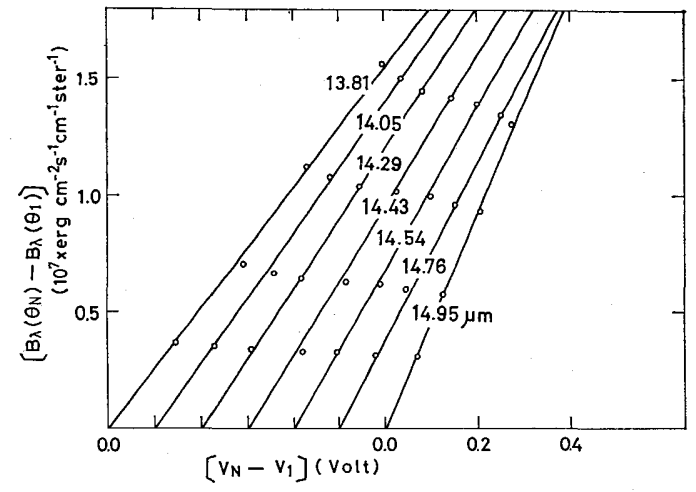

Fig. 3. An example of calibration curves by the 'subtract method'.

$$
\begin{aligned}
& {\left[B_{\lambda}\left(\theta_{N}\right) T_{\lambda}+E_{\lambda}\left(\theta_{a}\right)\right]} \\
& \quad-\left[B_{\lambda}\left(\theta_{r}\right) T_{\lambda, r}+E_{\lambda, r}\left(\theta_{a}\right)\right]=\alpha V_{N},
\end{aligned}
$$

where

$\theta$ : temperature of the black body

$T:$ transmittance through the spectrometer

$\alpha$ : a proportional constant

$E$ : thermal emission from the inside of the instrument

and subscripts $\lambda, a, r$ and $N$ denote respectively the wavelength, environmental atmosphere, reference black body and number of measurements. By changing the temperature of the black body the following equation is derived from Eq. (20) :

$$
\left[B_{\lambda}\left(\theta_{N}\right)-B_{\lambda}\left(\theta_{1}\right)\right]=\left(\alpha / T_{\lambda}\right)\left(V_{N}-V_{1}\right) .
$$

An example of plots of $\left[B_{\lambda}\left(\theta_{N}\right)-B_{\lambda}\left(\theta_{1}\right)\right]$ versus $\left(V_{N}-V_{1}\right)$ is shown in Fig. 3. The instrument constants $\left(\alpha / T_{\lambda}\right)$ were determined from the curves. In the figure the standard deviation of $\left[B_{\lambda}\left(\theta_{N}\right)-B_{\lambda}\left(\theta_{1}\right)\right]$ from the curves is less than $0.5^{\circ} \mathrm{C}$ at all wavelengths. The wavelengths used here are 13.81, 14.05, 14.29, $14.43,14.54,14.76$ and 14.95 in $\mu \mathrm{m}$ as Wang et al. (1975) employed.

\section{Results and discussions}

The intensities in the wing regions of the $15 \mu \mathrm{m} \mathrm{CO}$ band measured by our spectrometer system differ somewhat from those calculated by using the transmission functions quoted from Wang et al. (1975) and the atmospheric temperature profiles which were simultaneously observed by radiosonde. In order to correct the discrepancy the following factor $A(Z)$ is multiplied by the transmission function given by Wang et al. (1975):

$$
\tau_{\lambda}^{*}(Z)=\tau_{\lambda}(Z) A_{\lambda}(Z),
$$

where $A_{\lambda}(Z)$ is a correction factor depending on wavelength and height whose typical values are nearly equal to unity except for $13.81 \mu \mathrm{m}$. The correction factors of $13.81 \mu \mathrm{m}$ are shown in Table 2. The values of $\gamma_{1}$ and $\gamma_{2}$ described in the previous section are related to each other and determined to be $0.57 \times 10^{-2}$ and $0.32 \times 10^{-5}$ respectively by numerical simulations. The most suitable number of the terms of expansion of $B_{\lambda_{0}}[T(Z)]$ is found to be 15 at $\lambda_{0}=14.43 \mu \mathrm{m}$.

\subsection{Results}

a) clear sky

The measurements were made at the Tateno Aerological Observatory in the Tsukuba district about $50 \mathrm{Km}$ northeast of Tokyo, where routine observations of vertical profiles of temperature and humidity have been carried on for many years.

In Fig. $4 \mathrm{a}$ to Fig. $4 \mathrm{c}$ are shown the comparison between the profiles inferred and those observed with radiosondes. In Fig. $4 \mathrm{a}$, the inferred profile agrees well with the observed one. There are, however, some discrepancies between them: There exsists an inversion layer with a peak of about $300 \mathrm{~m}$ height in the observed profile, while an inversion layer

Table 2. Correction factor $A_{\lambda}(Z)$ at wavelength $13.81 \mu \mathrm{m}$.

\begin{tabular}{c|c|c|c|c|c|c|c|c}
\hline$\lambda(\mu \mathrm{m})$ & 0.0 & 0.1 & 0.3 & 0.5 & 0.8 & 1.5 & 3.0 & 6.0 \\
\hline 13.81 & 1.00 & 1.003 & 1.010 & 1.016 & 1.025 & 1.045 & 1.084 & 1.084 \\
\hline
\end{tabular}




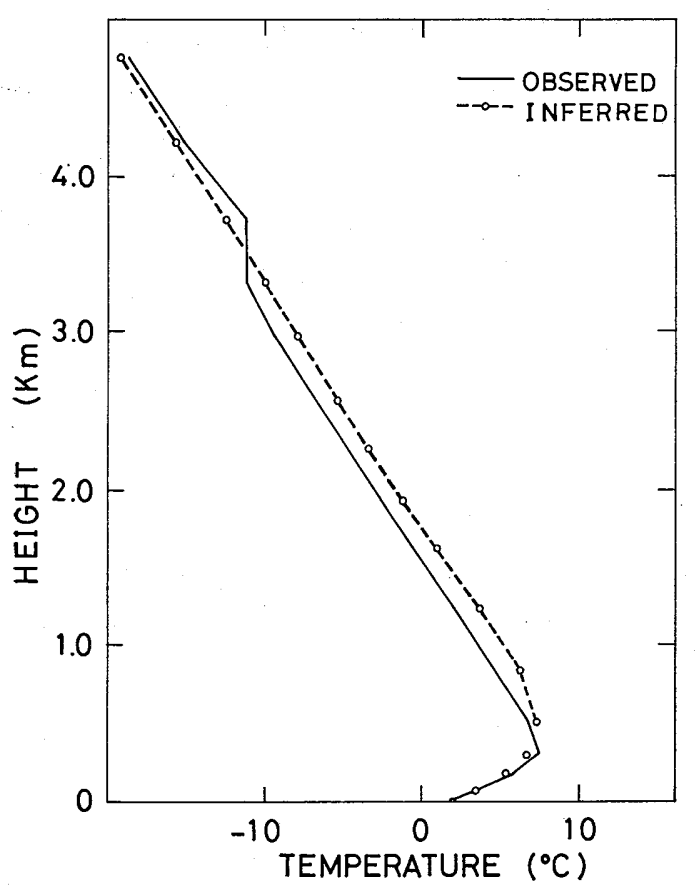

Fig. 4a. Comparison between the inferred temperature profile and the observed by radiosonde for the case of clear sky, 08: 30, 27 January 1978.

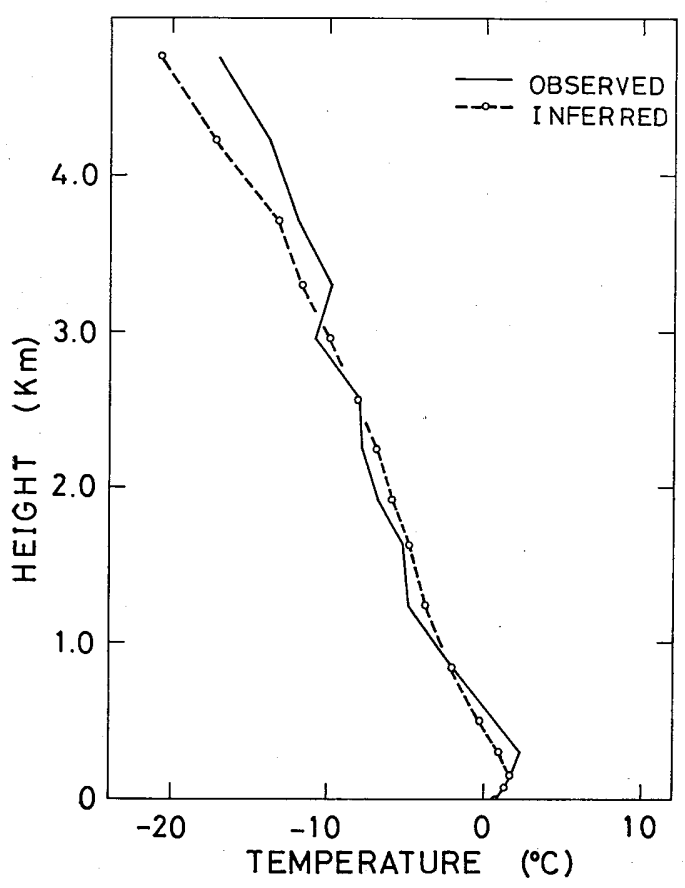

Fig. 4b. Same as Fig. 4a but for 20:30, 28 January 1978.

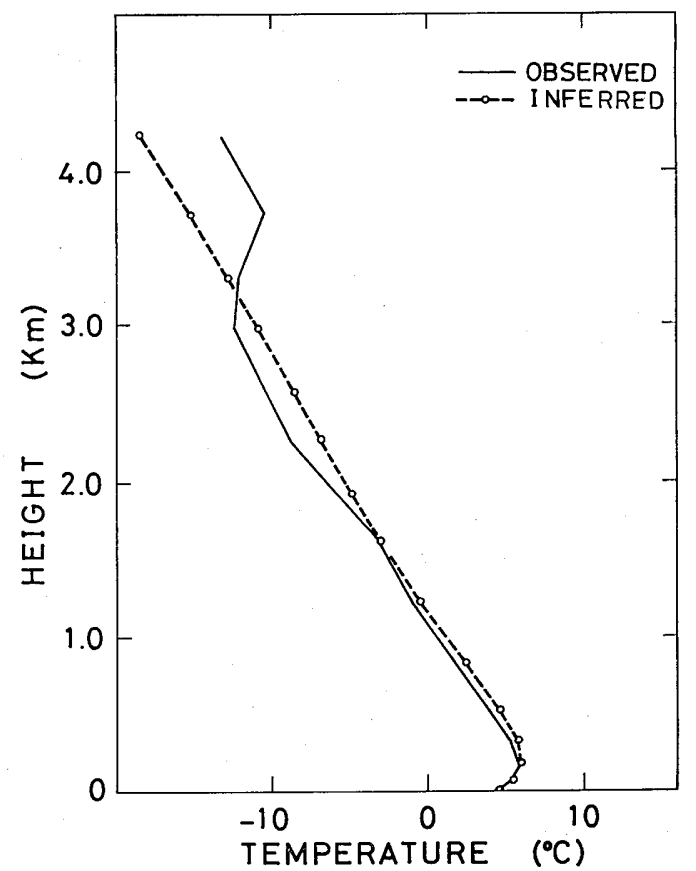

Fig. 4c. Same as Fig. 4a but for 20:30, 27 January 1978.

with a peak of about $450 \mathrm{~m}$ height in the inferred profile. In Fig. $4 \mathrm{~b}$, there is an agreement between the inferred profile and the observed one below the height of $3.0 \mathrm{Km}$. Above this height the agreement becomes worse. In Fig. 4c two profiles agree well with each other in the lower layer, i. e. below about $2.5 \mathrm{Km}$, but they differ considerably from each other beyond the height of $2.5 \mathrm{~km}$, especially beyond $3.5 \mathrm{Km}$. Generally the inferred profiles agree well with the observed ones. There, however, exist some discrepancies between them. The reasons for this are the following. The first is error in the measurement of spectral radiances. The second is the uncertainties of atmospheric transmission functions. The third is insufficient information on the higher layer in the case of groundbased measurements owing to the inherent nature of the waiting function. The fourth is error in measurements with radiosondes which is said to be $1^{\circ} \mathrm{C}$ or so.

b) Cloudy sky

Figs. $5 \mathrm{a}$ and $5 \mathrm{~b}$ show the inferred profiles in the cases of overcast sky. Fig. $5 \mathrm{a}$ is for 
the case of high cloud with an estimated cloud base temperature of $-18.0^{\circ} \mathrm{C}$ and an estimated

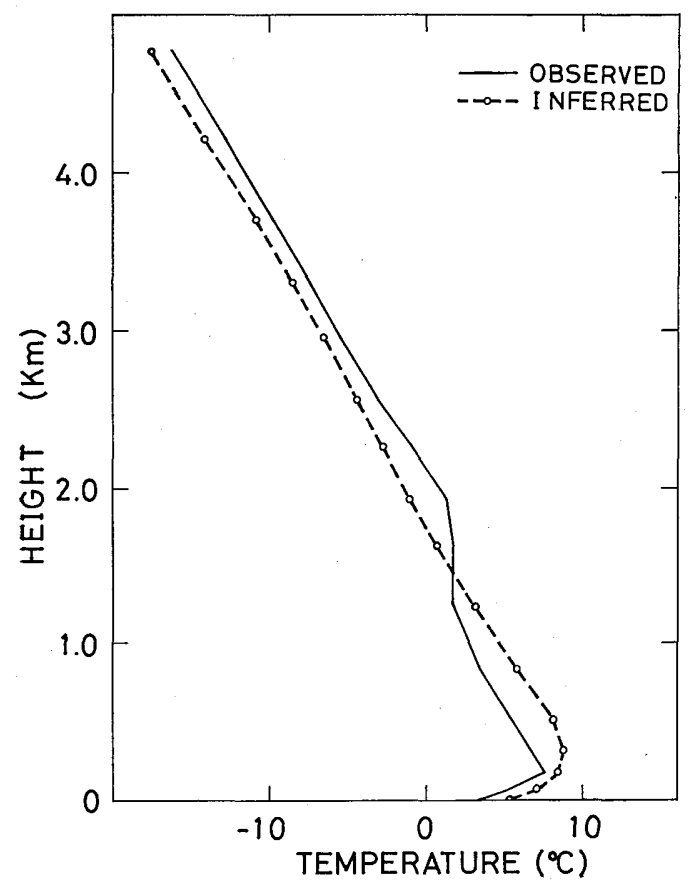

Fig. 5a. Comparison between the inferrd temperature profile and the observed by radiosonde for the case of overcast sky, 20: 3025 January 1979.

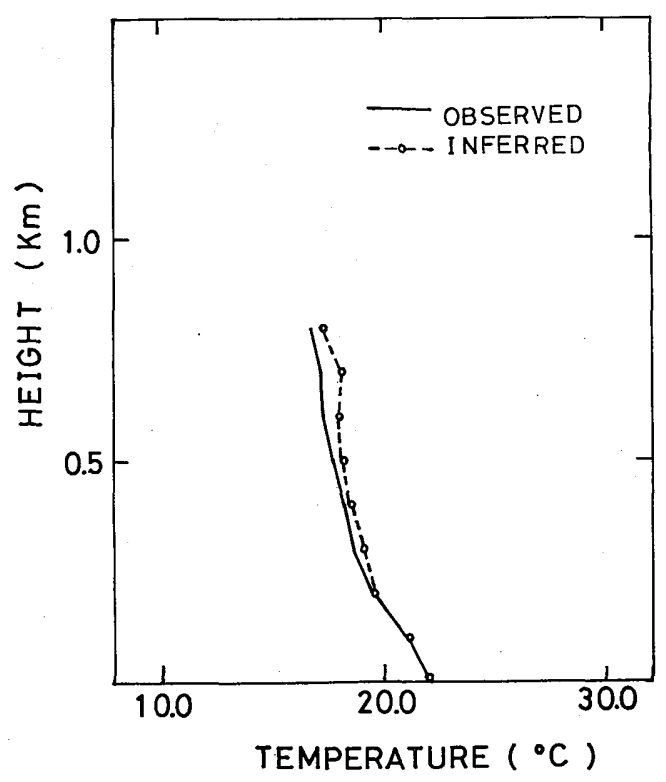

Fig. 5b. Same as Fig. 5a but for 08: 30 13 July 1979. height of about $5.0 \mathrm{Km}$ according to Eq. (19). Fig. $5 b$ is the case of low cloud whose temperature and base height are estimated to be $18.0^{\circ} \mathrm{C}$ and $0.8 \mathrm{Km}$, respectively. If the cloud is higher, its effect on the inferred profile becomes less. From these figures it can be seen that the inferred profiles agree with the observed ones in spite of the presence of clouds.

In the case of variable atmospheric conditions such as a partly cloudy sky reliable measurement of thermal radiation is difficult for much scanning time needed in carrying out with our measurement system. Then a few numerical simulations were carried out. Two atmosphric temperature profiles were chosen. One has a single inversion, and the other double inversions. Figs. $6 \mathrm{a}$ and $6 \mathrm{~b}$ show comparisons between the inferred temperature profiles and the given profiles. In these figures the cloud height is $3.1 \mathrm{Km}$ and the fractional cloud amount $w$ is 0.5 . The inferred profiles generally agree well with the given ones.

\subsection{Discussions}

Inferences on the temperature profile based on spectral radiation measurement are satisfactory under clear and overcast sky conditions. In these cases the differences between the inferred profile and the measured profile by radiosondes is found to be less than $2.0^{\circ} \mathrm{C}$ in the lowest layer of the atmosphere from the ground to $3.0 \mathrm{Km}$. Under the condition of overcast sky the temperature profile above the cloud can not be inferred because of no information from the layers above the cloud.

In the case of partly cloudy sky, there are two problems to be solved. The first is the difficulty of obtaining reliable spectral radiances with our measurement system as mentioned above. In order to overcome the disadvantage, we have to use a rapidly scanning spectrometer such as a Fourier Transform Infrared Radiometer instead of a grating spectrometer. The second is the numerical method in which the profiles inferred are liable to serious errors when the atmosphere contains much humidity as in summer since the e-type absorption in the atmospheric 


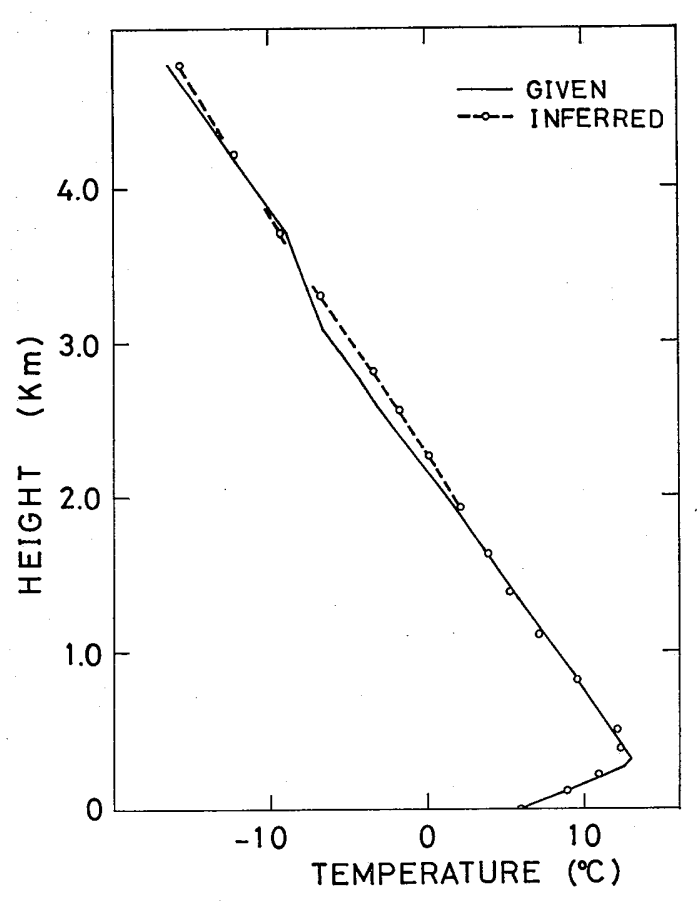

(a)

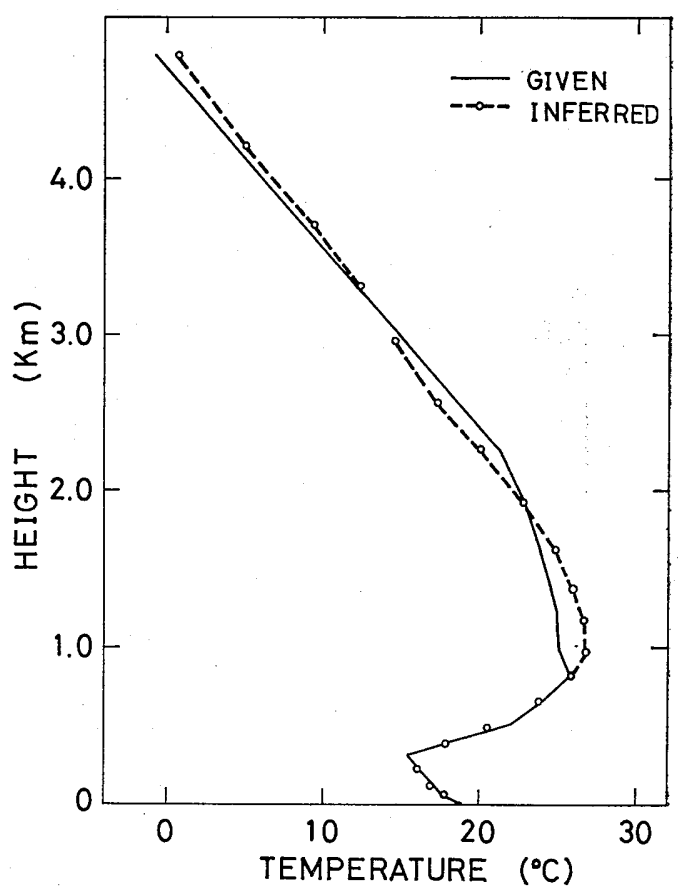

(b)

Figs. 6a and 6b. Inferred temperature profiles for the case of partly cloudy sky.

window region becomes strong. Furthermore in the case of a multi-layer cloud it is difficult to obtain reliable profiles. We will deal with these problem in the near future.

Acknowledgements:-The authors wish to thank Mr. M. Suzuki and Mr. H. Ikegami for their help in the measurements of spectral radiances. They also thank Mis. M. Uno for drawing picture and other asistance in this work.

\section{Reference}

Alishouse, J.C., L. J. Crone, H.E. Fleming, F.L. Van Cleef and D. Q. Wark, 1967: A discussion of empirical orthogonal functions and their application to vertical temperature profiles. Tellus, 19, 477-482.

Bingnell, K, J., 1970: The water vapor infrared continuum. Quart. J. Roy. Met. Soc., 96, 390403.

Chahine, M.T., H.H. Auman and F.W. Taylor, 1977: Remote sounding of cloudy atmosphere. III. Experimental verifications. J. Atmos. Sci., 34, 758-765.
Cox, S. K., 1973: Infra-red heating calculations with a water vapor pressure broadened continuum. Quart. J. Roy. Met. Soc., 99, 669-679.

Miner, G.F., D.D. Thornton and W.J. Welch, 1972: The inference of atmospheric temperature profile from ground-based measurements of microwave emission from atmospheric oxigen. J. G. R., 77, 975-991.

Phillips, D.L., 1962: A technique for the numerical solution of certain integral equations of the first kind. J. Assoc. Comp. Mach., 9, 84-97.

Smith, W.L., 1968: An improved method for calculating tropospheric temperature and moisture from satellite radiometer measurements. Month. Weath. Rev., 96, 387-396.

Snider, J.B., 1972: Ground-based sensing of temperature profiles from angular and multispectral microwave emission measurements. J. Appl. Met., 11, 958-967.

Twomey, S., 1963: On the numercal solution of Fredholm Integral Equations of the First Kind by inversion of the linear system produced by quadrature. J. Assoc. Comp. Mach., 10, 97101.

Wang, J. Y., C. R. Claysmith and M. Griggs, 1975 : Measurement of lower atmospheric temperature profiles from ground-based infrafed obser- 
vation. J. Appl. Met., 14, 308-318.

Wark, D. Q. and H.E. Fleming, 1966: Indirect measurements of atmospheric temperature profiles from satellites. Month. Weath. Rev., 94,
351-362.

Westwater, E. R., 1972: Ground-based determination of low altitude temperature profiles by microwaves. Month. weath. Rev., 100, 15-28.

\section{地上設置型分光計による大気温度の推定}

\section{宮内正厚・嘉納宗靖}

地上設置型分光計を使用して大気放射を分光測定することにより下層大気の気温の垂直分布を推定することを試 みた。晴天の時と全天雲に覆われている時は分光計の測定值から大気温度を推定し，その結果はラジオゾンデによ る直接測定值とよい一致を示した。一方雲にきれ間のある時, 分散型分光計では分光計の視野角内の雲量の変化に 伴う測定誤差が生じることからそのままの測定值を使用することができなかったので我々は数值実験を行った。そ の結果夏大気のよらな高温高湿の条件を除いて一応の成果が得られた。 